\section{Response to: 'Can biomarkers differentiate psoriatic arthritis from osteoarthritis?' by Tian et al}

We thank the authors for their interest in our paper that demonstrated that a panel of biomarkers may distinguish psoriatic arthritis (PsA) from osteoarthritis (OA). ${ }^{1}$ We agree with the comments that diagnostic biomarkers are most useful when the two diseases are difficult to distinguish clinically especially at earlier stages. PsA and OA may be hard to distinguish when the distal (distal interphalangeal (DIP), proximal interphalangeal (PIP)) joints are predominantly involved. Moreover, when patients with psoriasis develop joint pain, it may be difficult to distinguish OA from PsA. ${ }^{2}$ As a first step towards improving diagnostic ability using molecular biomarkers, in this particular study we aimed to provide proof of principle that a select panel of markers is able to distinguish between the two diseases using samples from patients with well-established disease. We did not adjust for disease severity since most patients with OA had advanced disease, and there is no common method to measure radiographic severity of OA and PsA. The association with disease severity was not investigated since that would be a different research/clinical question. As stated in Chandran et $a l,{ }^{3}$ future verification and validation studies will be conducted to examine the utility of this model in independent samples and to investigate whether other markers are identified for distinguishing OA from PsA in patients with psoriasis, particularly in the early disease stages.

We could have tested other markers, some of which have been mentioned. We chose a limited set of markers of cartilage metabolism, metabolic syndrome and inflammation/immune response. The reasons behind our choice are discussed in the discussion section of the paper. Additional markers as suggested by the authors of the letter are of interest and will be tested for inclusion in our prediction model if the current model fails further validation.

Vinod Chandran $\odot,{ }^{1}$ Richard J Cook, ${ }^{2}$ Dafna D Gladman $\odot^{3}$
${ }^{1}$ Medicine, University of Toronto, Toronto, Ontario, Canada

${ }^{2}$ Statistics and Actuarial Science, University of Waterloo, Waterloo, Ontario, Canada

${ }^{3}$ Department of Medicine, Rheumatology, University of Toronto, Toronto, Ontario,

Canada

Correspondence to Professor Dafna D Gladman, University of Toronto, Toronto, ON M5S, Canada; dafna.gladman@utoronto.ca

Handling editor Josef S Smolen

Funding The authors have not declared a specific grant for this research from any funding agency in the public, commercial or not-for-profit sectors.

Competing interests None declared.

Patient consent for publication Not required.

Provenance and peer review Commissioned; internally peer reviewed.

(C) Author(s) (or their employer(s)) 2020. No commercial re-use. See rights and permissions. Published by BMJ.

\section{Check for updates}

To cite Chandran V, Cook RJ, Gladman DD. Ann Rheum Dis 2020;79:e113.

Received 27 June 2019

Accepted 27 June 2019

Published Online First 4 July 2019

\section{SPlinked}

http://dx.doi.org/10.1136/annrheumdis-2019-215745

Ann Rheum Dis 2020;79:e113. doi:10.1136/annrheumdis-2019-215762

\section{ORCID iDs}

Vinod Chandran http://orcid.org/0000-0002-8297-0275

Dafna D Gladman http://orcid.org/0000-0002-9074-0592

\section{REFERENCES}

1 Tian J, Cheng C, Zhang F. Can biomarkers differentiate psoriatic arthritis from osteoarthritis? Ann Rheum Dis 2020;79:e112.

2. McGonagle D, Hermann K-GA, Tan AL. Differentiation between osteoarthritis and psoriatic arthritis: implications for pathogenesis and treatment in the biologic therapy era. Rheumatology 2015;54:29-38.

3. Chandran V, Abji F, Perruccio AV, et al. Serum-Based soluble markers differentiate psoriatic arthritis from osteoarthritis. Ann Rheum Dis 2019;78:796-801. 